\title{
TEORIA DA HISTÓRIA E A FORMAÇÃO DO PROFESSOR-PESQUISADOR
}

\author{
Prof. Dra. Maria Abadia Cardoso ${ }^{1}$ \\ Prof. Dr. Rodrigo de Freitas Costa ${ }^{2}$
}

As questões relativas à Teoria da História e à formação do professor-pesquisador já foram alvos de intensos debates. Se a primeira traz subsídios que permitem compreender a História como um campo disciplinar e seus respectivos elementos, tais como, interesses, singularidades, diálogos interdisciplinares, aspectos teóricos, metodológicos e expressivos, rede humana e interditos (RÜSEN, 2001; BARROS, 2011); a segunda articula-se frente à elementos que permitem a constituição da figura do historiador, uma vez que sua profissionalização implica em lidar: com uma diversidade de fontes e o aparato metodológico para tratá-las, com o estabelecimento de diálogo com outras áreas de conhecimento, com a construção de problemas e, fundamentalmente, sua atividade implica em escolhas, triagem, pontos de vista e hipóteses. (REIS, 2011). Em outras palavras, “[...] a teoria desempenha um importante papel na profissionalização didática dos historiadores". (RÜSEN, 2011, p. 38)

Desse modo, darão colorido especial a esse complexo campo da Teoria da História as indagações sobre a História como "ciência" ou arte (GINZBURG, 2002; VEYNE, 1987; WHITE, 1994; CERTEAU, 2002), sobre o uso de fontes (AROSTEGUI, 2006; PROUST, 2008), sobre os objetos de interesse do historiador e sua respectiva construção de tempo e de periodização (LE GOFF, 2013; THOMPSON, 1998; HOBSBAWN, 1998) e a articulação entre as temporalidades (KOSELLECK, 2006; HUIZINGA, 1939), para além das definições de Escolas Históricas (BOURDÉ; MARTIN, 1990) e Paradigmas Historiográficos (BARROS, 2013; REIS, 2004), dentre outros elementos.

\footnotetext{
${ }^{1}$ Professora do Instituto Federal de Educação Ciência e Tecnologia - IFG - Câmpus Goiânia - email: ma_cardoso_h@hotmail.com)

2 Professor Adjunto do Departamento de História da Universidade Federal do Triângulo Mineiro e Professor Colaborador do Programa de Pós-Graduação em História/UFU - email: rfreitascosta13@gmail.com)
} 
Se o cotidiano do historiador se constitui em meio à Teoria da História (RÜSEN, 2001), faz-se necessário indagar sobre o "lugar" e o papel da Teoria da História para a formação e atuação do professor de História. Não sem fundamento e pertinência, a relação entre o pesquisador e o professor ou entre a teoria e a prática, postas no Brasil desde o início da década de 1980 (MARSON; VESENTINI, 1982), e ampliada pela recepção e apropriação das ideias da Didática da História (BERGMAN, 1990; RÜSEN, 2006) permeiam uma constelação de questões e desafios relativos ao Ensino de História, o qual tem adquirido cada vez mais espaço em eventos e publicações na área.

Adotando diferentes categorias, é possível afirmar que entre a Teoria da História e o Ensino de História existem elementos tanto da Cultura Histórica quanto da Cultura Escolar (SCHMIDT, 2012), o que, consequentemente, permite pensar o segundo frente à sua própria historicidade e demanda.

Assim, o referido dossiê propõe pensar, em termos temáticos, teóricos e metodológicos, o "lugar" e o papel da Teoria da História na constituição do Ensino de História. Problematizando o modo como esse campo consolida de maneira específica, dentre outros, os debates sobre a concepção de História, as diferentes narrativas construídas nos livros e materiais didáticos, a dimensão histórica dos currículos, o amadurecimento de um repertório teórico e metodológico para o uso de diferentes fontes e linguagens em sala de aula, os modos distintos de pensar a dimensão temporal e, fundamentalmente, a relação entre saber histórico acadêmico e saber histórico escolar.

Segue uma breve descrição dos artigos que compuseram o presente dossiê:

No artigo "O ENSINO DE HISTÓRIA E A CULTURA AFRO-BRASILEIRA E AFRICANA SOB PERSPECTIVAS TEÓRICAS E PRÁTICAS: A LEI 10.639/03 REVISADA APÓS 15 ANOS" as autoras Talitta Tatiane Martins Freitas e Amanda Souza Santos discutem a implementação da lei 10.639/03 que prevê a obrigatoriedade do ensino de História da África e de cultura afro-brasileira nos centros de ensino do Brasil problematizando-a como fruto de uma demanda social que não apenas serve a um grupo específico, mas que contribui de maneira veemente com o processo de ensinoaprendizado voltado para a criticidade, autonomia do educando, para o exercício pleno da cidadania, bem como para a formação de uma sociedade aberta às diversidade culturais, religiosas, étnicas e sociais.

No artigo "OS FUNDAMENTOS TEÓRICOS DA DIDÁTICA DA HISTÓRIA E SUA APLICAÇÃO NO ENSINO ESCOLAR DA HISTÓRIA" os autores Luiz Carlos Bento e Carina Bonny realizam uma reflexão sobre os fundamentos 
teóricos da didática da história com base nos estudos de Jörn Rüsen e Klaus Bergmann problematizando as teorias destes autores como possibilidades para pensar o conhecimento histórico enquanto fruto de uma teia de fatores que interagem subjetivamente em um sujeito portador de uma consciência histórica que se forma através de processos complexos.

No artigo "DECOLONIZAR A COGNIÇÃO HISTÓRICA: EM BUSCA DE OUTRAS EPISTEMES PARA O ENSINO DE HISTÓRIA" o autor Rafael Gonçalves Borges realiza um esforço de aproximação entre duas perspectivas teóricas que se apresentam como linhas de pesquisa e atuação no cenário intelectual brasileiro. A primeira delas diz respeito às reflexões sobre o ensino de História a partir da Didática da História e sua preocupação em tematizar a consciência histórica como ponto de partida e chegada do ensino da disciplina, favorecendo a cognição e a literacia históricas. A segunda linha é a que parte do pensamento decolonial e de seu repertório conceitual para interpretar as sociedades $\mathrm{e}$ as práticas sociais do mundo pós-colonial. $\mathrm{O}$ autor problematiza quais possíveis contribuições podem ser oferecidas ao ensino de História enquanto prática e à Didática da História enquanto subdisciplina da ciência histórica, considerando o modo pelo qual epistemologias marginalizadas pelo pensamento Ocidental de matriz eurocêntrica influem na cultura histórica de sociedades não modernas.

No artigo "Aprendizagem histórica e docência entre a teoria e a prática: notas de um possível horizonte para o ensino de história" a autora Ana Paula Hilgert de Souza discute os estudos em educação histórica que adentraram na historiografia brasileira por meio das pesquisas desenvolvidas pela historiadora portuguesa Isabel Barca e da interlocução entre o pesquisador Estevão Chaves de Rezende Martins e o teórico da história e filosofia, Jörn Rüsen. Seu artigo propõe um exame acerca da influência do historiador e filósofo alemão, e de sua teoria, para o ensino da história, a partir do diálogo com outros historiadores que integram esse campo de investigação.

No artigo "IDENTIDADE HISTÓRICA E HEGEMONIA: A CONSTITUIÇÃO DA REPRESENTAÇÃO POSITIVA DOS AFRODESCENDENTES NO BRASIL" o autor e a autora Dagmar Manieri e Andreia Costa Souza propõem um estudo sobre o conceito de hegemonia aplicado à pesquisa sobre as lutas dos afrodescendentes no Brasil em torno da constituição da identidade histórica. Utilizam uma perspectiva teórica amparada nos trabalhos de Ernesto 
Laclau. Neste campo do saber, o artigo objetiva oferecer ao professor-pesquisador um exemplo de subsídio teórico para sua prática educacional.

No artigo "A REPRESENTAÇÃO DOS POVOS INDÍGENAS DO BRASIL NO LIVRO DIDÁTICO DE HISTÓRIA PROJETO ARARIBÁ" o autor Carlo

Guimarães Monti analisa como se insere a representação dos povos indígenas no livro didático do $7^{\circ}$ ano do Ensino Fundamental. Explorando a discussão racial do século XIX até o século XX no Brasil e suas influências no discurso de construção da identidade do povo brasileiro. $\mathrm{O}$ artigo tem por fim verificar se as propostas educacionais estão sendo aplicadas no que tange à temática indígena, conforme a legislação (as Leis $n^{\circ}$ 10.639/03 e $\mathrm{n}^{\circ} 11.645 / 08$, que propõe a valorização da diversidade étnico-racial, assim como o estudo das contribuições dos negros e indígenas na história do Brasil e na formação da nação), no livro didático Projeto Araribá, do $7^{\circ}$ ano do Ensino Fundamental.

No artigo "ENSINO DE HISTÓRIA E HISTÓRIA CULTURAL: POSSIBILIDADES PARA A CONSTRUÇÃO DO REPERTÓRIO DO PROFESSOR-PESQUISADOR" a autora Maria Abadia Cardoso problematiza o "lugar" da Teoria para a construção do repertório do professor-pesquisador. Evidencia a autora que esse campo é inerente à pesquisa e ao ensino de História e enfoca as possibilidades trazidas pela divisão intradisciplinar, em específico, e as contribuições trazidas pela História Cultural.

A presente edição é constituída ainda por artigos livres com temas diversificados concernentes à História. 